\title{
Towards a Hylomorphic Solution to the Grounding Problem
}

\author{
KATHRIN KOSLICKI
}

\begin{abstract}
Concrete particular objects (e.g. living organisms) figure saliently in our everyday experience as well as our in our scientific theorizing about the world. A hylomorphic analysis of concrete particular objects holds that these entities are, in some sense, compounds of matter (hüle $)$ and form (morphe or eidos). The Grounding Problem asks why an object and its matter (e.g. a statue and the clay that constitutes it) can apparently differ with respect to certain of their properties (e.g. the clay's ability to survive being squashed, as compared to the statue's inability to do so), even though they are otherwise so much alike. In this paper, I argue that a hylomorphic analysis of concrete particular objects, in conjunction with a non-modal conception of essence of the type encountered for example in the works of Aristotle and Kit Fine, has the resources to yield a solution to the Grounding Problem.
\end{abstract}

\section{The Grounding Problem}

Coincidence theorists, also known as 'pluralists' or 'multi-thingers', hold that numerically distinct objects can occupy the very same region of spacetime, while 'monists' or 'one-thingers' deny this claim. Why should we believe that numerically distinct objects can occupy the very same region of spacetime? Consider, for example, a statue and the lump of clay that constitutes it. In a typical case, these objects differ, among other things, with respect to their temporal properties: one comes into or goes out of existence before or after the other. But we can certainly imagine a case in which the statue and the lump of clay that constitutes it come into and go out of existence at exactly the same time, as is the case for example in Allan Gibbard's well-known scenario involving Lumpl and Goliath: ${ }^{1}$

I make a clay statue of the infant Goliath in two pieces, one the part above the waist and the other the part below the waist. Once I finish the two halves, I stick them together, thereby

1 Allan Gibbard, 'Contingent Identity', Fournal of Philosophical Logic $4(1975), 187-221$. 


\section{Kathrin Koslicki}

bringing into existence simultaneously a new piece of clay ['Lumpl'] and a new statue ['Goliath']. A day later I smash the statue, thereby bringing to an end both statue and piece of clay. The statue and the piece of clay persisted during exactly the same period of time. ${ }^{2}$

Even if the statue and the piece of clay imagined by Gibbard are indiscernible with respect to their temporal properties, they nevertheless appear to differ with respect to other properties. If indeed there are such properties with respect to which coincident objects differ, then Leibniz's Law dictates that these objects are numerically distinct, even though they occupy the very same region of spacetime. $^{3}$

What are these properties with respect to which coincident objects appear to differ? Prominent examples of such properties which are apparently not shared by coincident objects include the following: de re modal properties (e.g. being essentially or accidentally statueshaped); sortal or kind properties (e.g. being a statue or being a lump of clay); properties pertaining to their persistence conditions (e.g. being capable of being squashed or not being capable of being squashed); as well as evaluative or other types of properties (e.g. being innovative, valuable, well-made, expressing a certain content, etc.). ${ }^{4}$ Perhaps some of these apparent differences can be explained in terms of others, so that some of these properties may turn out to be derivative (or more derivative than others), while others may turn out to be basic (or less derivative than others). Karen Bennett calls those properties with respect to which coincident objects can apparently differ 'sortalish' properties; and she calls the remaining

\footnotetext{
2 Gibbard, 'Contigent Identity', 191.

3 According to Leibniz's Law, necessarily for all objects, $\mathrm{x}$ and $\mathrm{y}$, if $\mathrm{x}$ and $y$ are numerically identical (i.e. $x=y$ ), then $x$ and $y$ are qualitatively indiscernible (i.e. they have all the same properties and stand in all the same relations). Leibniz's Law should be distinguished from the much more controversial converse principle, the Identity of Indiscernibles, according to which necessarily for all objects, $\mathrm{x}$ and $\mathrm{y}$, if $\mathrm{x}$ and $\mathrm{y}$ are qualitatively indiscernible (i.e. have all the same properties and stand in all the same relations), then $\mathrm{x}$ and $\mathrm{y}$ are numerically identical (i.e. $\mathrm{x}=\mathrm{y}$ ). For further discussion of the cogency of Leibniz's Law style arguments for the numerical distinctness of coincident objects, see Kathrin Koslicki, 'Almost Indiscernible Objects and the Suspect Strategy', The Fournal of Philosophy 102 (2005), 55-77.

4 For illustrations along these lines, see for example Kit Fine, 'A Counter-example to Locke's Thesis', The Monist 83 (2000), 357-361.
} 


\section{Towards a Hylomorphic Solution to the Grounding Problem}

properties which are apparently shared by coincident objects 'nonsortalish' properties. ${ }^{5}$

Using Bennett's distinction between sortalish and non-sortalish properties, we can thus state the Grounding Problem as follows: given that coincident objects appear to share all of their non-sortalish properties, what grounds the apparent differences between them with respect to their sortalish properties? ${ }^{6}$ Although the Grounding Problem has been raised as an objection primarily against pluralists, monists as well must formulate some kind of response to the Grounding Problem. For if, as monists hold, each region of spacetime is occupied by only a single object, then we wonder why it is the case that we nevertheless find ourselves attributing apparently contradictory properties to this single object. ${ }^{7}$

As Bennett points out, ${ }^{8}$ the distinction between sortalish and nonsortalish properties should not be confused with the distinction between intrinsic and extrinsic properties, since coincident objects share both intrinsic and extrinsic properties; and the sortalish properties with respect to which they appear to differ may also include both intrinsic and extrinsic properties, depending on one's view concerning these properties. Thus, the Grounding Problem does not ask how coincident objects which are intrinsically alike can apparently differ from each other in other non-intrinsic respects.

Bennett considers three types of responses to the Grounding Problem: (i) non-sortalish grounds: attempts to ground the sortalish

5 Karen Bennett, 'Spatio-temporal Coincidence and the Grounding Problem', Philosophical Studies 118 (2004), 341.

6 Bennett, 'Spatio-temporal Coincidence and the Grounding Problem', $341-342$.

7 For additional discussion of the Grounding Problem, see also Louis deRosset, 'What is the Grounding Problem?', Philosophical Studies: An International Fournal for Philosophy in the Analytic Tradition 156 (2011), 173-197; John Divers, 'Coincidence and Form', Proceedings of the Aristotelian Society, Supplementary Volume 82 (2008), 119-137; Kit Fine, 'Coincidence and Form', Proceedings of the Aristotelian Society, Supplementary Volume 82 (2008), 101-118; Mark Jago, 'Essence and the Grounding Problem', in Reality Making (ed.) Mark Jago (Oxford: Oxford University Press, 2016), 99-120; Eric Olson, 'Material Coincidence and the Indiscernibility Problem', The Philosophical Quarterly 51 (2001), 337-355; C. S. Sutton, 'Colocated Objects, Tally-Ho: A Solution to the Grounding Problem', Mind 121 (2012), 703-730; Dean Zimmerman, 'Theories of Masses', Philosophical Review 104 (1995), 53-110.
8 'Spatio-tempora $343-344$. 


\section{Kathrin Koslicki}

differences between coincident objects somehow in their non-sortalish properties (e.g. by way of a supervenience principle of some sort); (ii) conceptualism/conventionalism: attempts to attribute the apparent sortalish differences between coincident objects in some way to our concepts or conventions; and (iii) primitivism: the position that objects have whatever sortalish properties they in fact have primitively, and therefore nothing grounds the apparent sortalish differences between coincident objects. (Primitivism, in Bennett's view, is not so much a solution to the Grounding Problem as it is a denial that there is a genuine question in the vicinity which requires an answer.)

Bennett takes the first style of response to be hopeless: given that coincident objects share all the same non-sortalish properties, it is difficult to see how the apparent sortalish differences between them could be grounded in their non-sortalish properties, regardless of the various attempts to the contrary to concoct suitable supervenience principles. ${ }^{9}$ The second style of response is also unattractive, in Bennett's view, due to the questionable commitments it incurs: proponents of the second style of response must either hold that our concepts or conventions possess near-magical creative powers which they do not in fact seem to possess; or they must allow that objects can exist with no sortalish properties whatsoever prior to the imposition of such properties by means of our conceptual or conventional activities. ${ }^{10}$ Since Bennett takes both of these positions to be highly implausible, she urges pluralists not to opt for the second style of response to the Grounding Problem. The third option, viz. primitivism, is the best hope for pluralists, according to Bennett, though this response also comes with substantial costs. The apparent unattractiveness of primitivism can be alleviated, so Bennett argues, if pluralists take on board the following plenitude principle: '...every region of spacetime that contains an object at all contains a distinct object

9 See for example Lynne Rudder Baker, Persons and Bodies: A Constitution View (New York: Cambridge University Press, 2000); Michael Rea, 'Supervenience and Colocation', American Philosophical Quarterly 34 (1997), 367-375; Theodore Sider, 'Global Supervenience and Identity Across Times and Worlds', Philosophy and Phenomenological Research 59 (1999), 913-937; Dean Zimmerman, 'Theories of Masses'.

10 See for example Alan Sidelle, Necessity, Essence, and Individuation: A Defense of Conventionalism (Ithaca: Cornell University Press, 1989); 'Rigidity, Ontology, and Semantic Structure', The Yournal of Philosophy 89 (1992), 410-430. 


\section{Towards a Hylomorphic Solution to the Grounding Problem}

for every possible way of distributing 'essential' and 'accidental' over the non-sortalish properties actually instantiated there'). ${ }^{11}$ Bennett argues that, given this plenitude principle, the question of why any particular sortalish profile is instantiated in a given region of spacetime can be answered by pointing to the fact that every possible such sortalish profile is instantiated in the same region of spacetime.

\section{A Hylomorphic Analysis of Concrete Particular Objects}

The Aristotelian doctrine of hylomorphism holds that those entities which are subsumed under it are, in some sense, compounds of matter $(h u l \bar{e})$ and form (morphe or eidos). Aristotle first introduced the distinction between matter and form in response to a problem concerning the possibility of change he had inherited from his Presocratic predecessors, according to which change is logically impossible since it requires either a transition from nothing to something or a transition from something to nothing. In response, Aristotle argued in Physics I that change is possible after all, since something (viz. the matter) always persists through any change that occurs, while something else (viz. the form or privation) does not persist through the change. For example, when some wood (the matter) goes from not being a bed (the privation) to being a bed (the form), the wood remains throughout the change, but the wood's not being a bed does not persist through the change. After Aristotle's initial application of the doctrine of hylomorphism to the problem of change, the distinction between matter and form became a cornerstone of his approach to nearly every central phenomenon discussed elsewhere in the corpus, including in his treatises on logic, natural science, metaphysics, theology, ethics, and political philosophy. I have argued that a hylomorphic approach to the metaphysics of concrete particular objects is well-positioned to compete with non-hylomorphic alternative conceptions of concrete particular

11 Bennett, 'Spatio-temporal Coincidence and the Grounding Problem', 354. See also Stephen Yablo, 'Identity, Essence, and Indiscemibility', The Fournal of Philosophy 84 (1987), 293-314, and 'Mental Causation', The Philosophical Review 101 (1992), 245-280, though Yablo's motivation for endorsing the plenitude principle is not driven by the desire to provide a response to the Grounding Problem. 


\section{Kathrin Koslicki}

objects when evaluated against a range of measures of success. ${ }^{12}$ The application of this doctrine to the specific case of concrete particular objects does not yield a single uniform hylomorphic approach. Rather, theorists who are drawn to the hylomorphic paradigm encounter a series of decision points and desiderata along the way, leading to a multiplicity of hylomorphic approaches to the metaphysics of concrete particular objects. ${ }^{13}$ These different hylomorphic

\section{See Kathrin Koslicki, The Structure of Objects (Oxford: Oxford} University Press, 2008); Form, Matter, Substance (Oxford: Oxford University Press, 2018).

13 For other defenses of a hylomorphic ontology, see for example Jeffrey Brower, Aquinas's Ontology of the Material World: Change, Hylomorphism, and Material Objects (Oxford: Oxford University Press, 2014); Simon Evnine, Making Objects and Events: A Hylomorphic Theory of Artifacts, Actions, and Organisms (Oxford: Oxford University Press, 2016); Kit Fine, 'Acts, Events and Things', Language and Ontology, Proceedings of the $6^{\text {th }}$ International Wittgenstein Symposium (1982), 97-105; Kit Fine, 'Things and Their Parts', Midwest Studies in Philosophy 23 (1999), 61-74; Verity Harte, Plato on Parts and Wholes: The Metaphysics of Structure (Oxford: Clarendon Press, 2002); William Jaworski, Structure and the Metaphysics of Mind: How Hylomorphism Solves the Mind-Body Problem (New York: Oxford University Press, 2016); Mark Johnston, 'Parts and Principles: False Axioms in Mereology', Philosophical Topics 30 (2002), 129-166; Mark Johnston, 'Hylomorphism', The Fournal of Philosophy 103 (2006), 652-698; Robert Koons, 'Staunch vs. Faint-Hearted Hylomorphism: Toward an Aristotelian Account of Composition', Res Philosophica 91 (2014), 151-177; E.J. Lowe, 'Form Without Matter', in Form and Matter: Themes in Contemporary Metaphysics (ed.) David Oderberg (Oxford: Blackwell, 1999), 1-21; Anna Marmodoro, 'Aristotle's Hylomorphism Without Reconditioning', Philosophical Inquiry 36 (2013), 5-22; Daniel D. Novotný and Lukáš Novák (eds), Neo-Aristotelian Perspectives in Metaphysics (New York: Routledge, 2014); David Oderberg, Real Essentialism (New York: Routledge Taylor \& Francis, 2007); Michail Peramatzis, Priority in Aristotle's Metaphysics (New York: Oxford University Press, 2011); Michael Rea, 'Hylomorphism Reconditioned', Philosophical Perspectives 25 (2011), 341-358; Thomas Sattig, The Double Lives of Objects (Oxford: Oxford University Press, 2015); Eleonore Stump, 'Non-Cartesian Substance Dualism and Materialism Without Reductionism', Faith and Philosophy 12 (1995), 505-531; Eleonore Stump, 'Emergence, Causal Powers, and Aristotelianism in Metaphysics', in Powers and Capacities in Philosophy: The New Aristotelianism (eds) Ruth Groff and John Greco (New York: Routledge, 2013), 48-68; Patrick Toner, 'On Hylemorphism and Personal Identity', European Fournal of Philosophy 19 (2011), 454-473; Patrick Toner, 'Hylemorphic Animalism', Philosophical Studies 155 (2011), $65-81$. 


\section{Towards a Hylomorphic Solution to the Grounding Problem}

conceptions of concrete particular objects, however, share a unique strength which, in my view, recommends these approaches over their non-hylomorphic competitors. Those who favor a hylomorphic approach have at their disposal the ability to attribute to concrete particular objects an internal structural complexity that is not recognized by non-hylomorphic alternatives, since hylomorphists associate with each concrete particular object two principles, matter and form, each performing its own range of characteristic explanatory tasks. Moreover, hylomorphists locate these two explanatory principles, in some sense, inside the objects with which they are associated (e.g. by counting them among the object's proper parts or constituents). This apparatus makes hylomorphism a highly flexible, effective and powerful tool for the metaphysical analysis of concrete particular objects and provides hylomorphists with explanatory options that are not, or at least not as readily, available to those who do not endorse the hylomorphic outlook. The availability of the distinction between matter and form, I argue, turns out to be useful to hylomorphists for the purposes of accounting for certain distinguishing characteristics of concrete particular objects, viz. in particular facts about their structure, identity and unity.

\section{Sidelle's Challenge to Hylomorphists}

Alan Sidelle has recently posed an interesting challenge for hylomorphists: ${ }^{14}$ depending on how these theorists conceive of the form present in a matter-form compound, hylomorphism either offers no solution to the Grounding Problem; or, if it does respond to the Grounding Problem at all, it does so in a way that is not proprietary to hylomorphism, and hence can be adopted by non-hylomorphic approaches to the metaphysics of concrete particular objects as well. Either way, so Sidelle reasons, hylomorphism fails to add anything distinctive to the dialectical situation pluralists face when attempting to explain what grounds the apparent differences between numerically distinct spatiotemporally coincident objects.

To arrive at the first horn of the dilemma (viz. that, according to certain conceptions of form, hylomorphism provides no solution to the Grounding Problem), Sidelle supposes, for the sake of the argument, that form is construed by hylomorphists as something along the lines of the organization or arrangement that is exhibited by an

14 Alan Sidelle, 'Does Hylomorphism Offer a Distinctive Solution to the Grounding Problem?', Analysis 74 (2014), 397-404. 


\section{Kathrin Koslicki}

object's material parts. Given this supposition, so Sidelle reasons, it is difficult to see why the matter composing a hylomorphic compound does not also exhibit the very same form as the hylomorphic compound itself. After all, while the matter in question composes the hylomorphic compound, both are of course organized and arranged in the very same manner, for as long as the entities in question are spatiotemporally coincident. At the same time, it is thought to be essential to the hylomorphic compound that its material parts are organized or arranged in the way that is dictated by the form in question, but only accidental to the matter composing the hylomorphic compound that these material parts are organized or arranged in this way. But now, so Sidelle argues, we can see that no progress at all has been made towards a distinctively hylomorphic solution to the Grounding Problem, given the conception of form currently under consideration. For the natural next question we want to pose is how it can be that the very same form belongs to a hylomorphic compound essentially, while it belongs to the matter composing it accidentally; and this question of course presents us with just another instance of the Grounding Problem. We have therefore apparently landed right back where we started and the appeal to form seems not to have contributed anything at all to providing a solution to the Grounding Problem.

The second horn of the dilemma (viz. that, under a different hypothesis, hylomorphism fails to provide a distinctive solution to the Grounding Problem) requires a conception of form that is robust enough to block the problematic move just outlined. According to this more robust conception, it is taken as a brute fact that the form which is essentially present in a hylomorphic compound does not also accidentally belong to the matter composing it. (This second response, thus, is a version of what we referred to earlier as 'primitivism'.) To illustrate, this approach assumes that no further explanation can be given as to why a statue, say, has a statue-form present in it, while the clay constituting the statue does not: statues, according to this conception, by their very nature have statue-forms present in them; and, since lumps of clay are not statues, lumps of clay by their very nature do not have statue-forms present in them.

While the account currently under consideration does not fall prey to the previous difficulty raised above, it does, in Sidelle's view, suffer from a different sort of weakness. For since the central thesis of hylomorphism (viz. that concrete particular objects are, in some sense, compounds of matter and form) seems to play no role in generating this second response to the Grounding Problem, the same style of response is also available to theorists who do not share the hylomorphic 


\section{Towards a Hylomorphic Solution to the Grounding Problem}

outlook. Instead of appealing to a brute formal difference between numerically distinct spatiotemporally coincident objects, these theorists can point to a brute difference of some other sort (e.g. a brute sortal difference, a brute difference with respect to persistence conditions, or what have you). Insofar as the second response provides a solution to the Grounding Problem, then, Sidelle considers it not to be proprietary to hylomorphism.

In addition, however, since the second response appeals to a brute difference between numerically distinct spatiotemporally coincident objects, Sidelle is skeptical as to whether it even yields a genuine solution to the Grounding Problem at all. For the question at issue was, after all, to say what grounds the differences between numerically distinct spatiotemporally coincident objects; and merely to point to the brute fact that there are such differences, without explaining how these differences arise, strikes Sidelle as not so much a solution to the Grounding Problem as 'a denial that the basic differences between the objects need to be grounded'. ${ }^{15}$ In any case, so Sidelle concludes, hylomorphists are guilty of false advertising, when they claim that their approach to the metaphysics of concrete particular objects is superior to others in that it yields a distinctive solution to the Grounding Problem which is not also available to those who do not endorse the basic hylomorphic premise.

\section{Towards a Hylomorphic Solution to the Grounding Problem}

In what follows, I argue for a robust hylomorphic pluralist response to Sidelle's challenge. This approach rejects the non-robust construal of form problematized in the first horn of the dilemma Sidelle poses for hylomorphists, according to which forms lack the robustness necessary to prevent them from simultaneously bearing the same relation both to the matter-form compound (essentially) and the matter composing it (accidentally). Instead, as I argue below, hylomorphists should embrace the robust construal of form problematized in the second horn of his dilemma. Hylomorphists who adopt a robust construal of form can respond to the remainder of Sidelle's challenge as follows. First, hylomorphists need not accept the responsibility of having to provide a distinctively hylomorphic solution to the Grounding Problem; rather, their response to the Grounding Problem may turn on features which can be utilized by hylomorphists

15 'Does Hylomorphism Offer a Distinctive Solution to the Grounding Problem?', 402. 


\section{Kathrin Koslicki}

and non-hylomorphists alike. (In that case, of course, as Sidelle correctly notes, hylomorphists should also not falsely advertise that their solution to the Grounding Problem is distinctively hylomorphic, when it in fact turns on features which can be adopted by other non-hylomorphic accounts as well.) In addition, I argue below for a version of robust hylomorphic pluralism which invokes independently motivated essential differences between coincident objects. When conjoined with a non-modal conception of essence, this response to the Grounding Problem outlines a strategy for explaining the derivative modal differences between coincident objects in terms of essential differences between them that are taken as basic by the account in question. ${ }^{16}$

\subsection{The Scenario}

Let's return once more to Gibbard's Lumpl and Goliath scenario cited earlier. Gibbard asks us to imagine a case in which a clay statue ('Goliath') is fashioned by sticking together two pieces of clay, the part above the waist and the part below the waist; once the two pieces of clay are stuck together, a new piece of clay ('Lumpl') comes into existence and the statue, Goliath, thereby simultaneously comes into existence as well. A day later, Goliath is smashed to pieces, thereby destroying Lumpl as well. ${ }^{17}$

16 I myself am guilty of Sidelle's charge that hylomorphists engage in false advertising when they claim that their account generates a distinctively hylomorphic solution to the Grounding Problem. I argued in The Structure of Objects (181ff) that a mere difference in formal parts between numerically distinct spatiotemporally coincident objects is sufficient to yield a distinctively hylomorphic solution to the Grounding Problem. I no longer hold this position. Instead, as I propose below, in addition to the independently motivated essential differences between coincident objects, I now believe that a non-modal conception of essence is also needed to formulate a credible response to the Grounding Problem. But hylomorphists and non-hylomorphists alike can help themselves to this strategy; hence, the resulting response to the Grounding Problem is not distinctively hylomorphic. As long as hylomorphists are careful not to engage in false advertising, however, they should not be concerned if the main features of their response to the Grounding Problem can be replicated by non-hylomorphists as well.

17 Although this particular case happens to involve artifacts, I assume that a case in which a concrete particular object and its matter are spatiotemporally coincident could, in principle, be constructed for living or non-living members of natural kinds as well. I thus intend my reasoning 


\section{Towards a Hylomorphic Solution to the Grounding Problem}

Following a hylomorphic analysis of concrete particular objects, Goliath is a matter-form compound consisting of some matter, $\mathrm{m}$, and a form, f. In what follows, I will refer to Goliath as ' $O$ ' (short for 'object') and use ' + ' to stand for the relation of hylomorphic composition by means of which $\mathrm{m}$ and $\mathrm{f}$ together give rise to $\mathrm{O}$. We can then state the hylomorphic claim that Goliath is a compound of some matter, $\mathrm{m}$, and a form, $\mathrm{f}$, as follows: ${ }^{18}$

$$
\mathrm{O}=\mathrm{m}+\mathrm{f}
$$

Presumably, hylomorphists will find it attractive to say that Lumpl, in Gibbard's story, just is (numerically identical to) $\mathrm{m}$, i.e. Goliath's matter.

Goliath's form, f, could be construed in a variety of ways, since the doctrine of hylomorphism as such, as well as its application to the specific case of concrete particular objects, leaves open to which ontological category forms belong. Proponents of the 'universal forms hypothesis', on the one hand, take forms to be universal or general entities that are in principle repeatable and can be shared among multiple distinct entities by being wholly present in each of them at a single time. Proponents of the 'individual forms hypothesis', on the other hand, take forms to be particular or individual entities that are by their very nature not repeatable or shareable among multiple distinct entities by being wholly present in each of them at a single time. ${ }^{19}$ Yet others, viz. the 'hybrid theorists', reject the dichotomy

in what follows to be completely general and not to turn on any characteristics that might be specific to the case of artifacts.

18 The representation in (1) is an oversimplification, since it ignores the possibility that $\mathrm{O}$ can persist through changes with respect to its matter over time. Thus, a more realistic representation of the claim that Goliath is a compound of some matter, $\mathrm{m}$, and a form, $\mathrm{f}$, would have to accommodate such possibilities as the following: Goliath exists at a time, $t_{1}$, and at a distinct time, $t_{2}$, and the matter, $m_{1}$, which composes Goliath at $t_{1}$ is distinct from the matter, $\mathrm{m}_{2}$, which composes Goliath at $\mathrm{t}_{2}$. For the sake of simplicity, I will in what follows continue to surpress the necessary relativization to time.

19 Within each of these camps, further choices are available depending on the more specific ontological category to which forms are assigned (see Koslicki, Form, Matter, Substance, Section III.2, for more detail). To illustrate, universal forms theorists have for example assigned forms to the following ontological categories (where the members of these ontological categories are of course, in each case, construed as universals): properties (e.g. Peramatzis, Priority in Aristotle's Metaphysics); relations (e.g. Johnston, 'Hylomorphism'); powers (e.g. Marmodoro, 'Aristotle's 


\section{Kathrin Koslicki}

between universal/general and individual/particular entities altogether and argue that forms do not neatly fit into either category, since they have features distinctive of both categories. ${ }^{20}$ I myself endorse a version of the individual forms hypothesis, mainly on the grounds that questions concerning the numerical identity of matter-form compounds, in particular their crossworld identity, are best resolved by appeal to individual forms. ${ }^{21}$

Further, our scenario involves the following three hylomorphic relations: the compound-form relation Goliath bears to its form, $\mathrm{f}$; the matter-form relation Lumpl bears to Goliath's form, f; and the

Hylomorphism Without Reconditioning'); or activities (e.g. Aryeh Kosman, The Activity of Being (Cambridge: Harvard University Press, 2013). Individual forms theorists, similarly, have a range of options available to them, depending on whether they take forms to be objects (e.g. Lowe, 'Form Without Matter'); properties, construed as particulars (e.g. Brower, Aquinas's Ontology of the Material World: Change, Hylomorphism, and Material Objects); states (e.g. Stump, 'Non-Cartesian Substance Dualism and Materialism Without Reductionism'); functions (e.g. Kit Fine, 'Things and Their Parts'); powers, construed as particulars (e.g. Jaworski, Structure and the Metaphysics of Mind: How Hylomorphism Solves the Mind-Body Problem); activities or processes, construed as particulars (e.g. Koons, 'Staunch vs. Faint-Hearted Hylomorphism: Toward an Aristotelian Account of Composition'); facts (e.g. Sattig, The Double Lives of Objects); or actions (e.g. Evnine, Making Objects and Events: A Hylomorphic Theory of Artifacts, Actions, and Organisms). In addition, if forms turn out not to fit into any previously recognized category, both universal and individual forms theorists (as well as the hybrid theorists I am about to mention) also have the option of designating forms as sui generis entities.

20 The hybrid position can be found for example in Alan Code, 'The Aporematic Approach to Primary Being in Metaphysics Z', in New Essays on Aristotle, Canadian Fournal of Philosophy, Supplementary Volume $\mathrm{X}$ (1984) (eds) Francis Jeffry Pelletier and John King-Farlow, 1-20; Mary Louise Gill, Aristotle on Substance: The Paradox of Unity (Princeton: Princeton University Press, 1989); and Rea, 'Hylomorphism Reconditioned'.

21 Since my own sympathies lie with the individual forms hypothesis, I will in what follows assume that forms are to be treated as particular or individual entities of some sort. Due to space constraints, I am unfortunately unable to justify this very controversial assumption in the present context. For a detailed discussion, see my Form, Matter, Substance, Section III.4.3; and 'Essence and Identity', forthcoming in Metaphysics, Meaning and Modality: Themes from Kit Fine (ed.) Mircea Dumitru (Oxford: Oxford University Press). 


\section{Towards a Hylomorphic Solution to the Grounding Problem}

matter-compound relation Lumpl bears to Goliath. Given the close connection between form and essence, hylomorphists will want to say that Goliath's form, $\mathrm{f}$, in some way figures in Goliath's essence: ${ }^{22}$

(2) f figures in O's essence.

In contrast, it is plausible to hold that Goliath's form, $f$, does not figure in Lumpl's essence, since Lumpl appears to be related to $f$ only accidentally:

(3) f does not figure in m's essence.

After all, even though Lumpl and Goliath, in Gibbard's scenario, come into and go out of existence at the same time, Lumpl nevertheless could have existed in a scenario in which Goliath does not exist and in which Lumpl is not coincident with any other statue. In such a scenario, Lumpl would have existed without being related to Goliath's form, f, or to Goliath. Lumpl, therefore, is only accidentally related to Goliath's form, f, and f does not figure in Lumpl's essence.

At this point, an apparent sortalish difference between Lumpl and Goliath has emerged, as is brought out in (2) and (3): while both Lumpl and Goliath stand in some relation to the very same entity, viz. Goliath's form, $f$, this form figures only in Goliath's essence but not in Lumpl's. The Grounding Problem, in its current incarnation, now asks what (if anything) explains this apparent sortalish difference between Lumpl and Goliath:

Sortalish Difference: In virtue of what it is the case that $\mathrm{f}$ figures in O's essence, but not in m's essence?

Different hylomorphists will answer (4) differently, depending in part on how they approach the following questions:

Compound-Form Relation: How is a matter-form compound related to its form?

22

The term, 'figure', is intentionally vague to allow for different ways of filling in the relation between form and essence. Proponents of the individual and universal forms hypothesis alike have the option of holding either that the essence of a matter-form compound is exhausted by (i.e. identical to) its form or that the essence of a matter-form compound includes but is not exhausted by its form, e.g. on the grounds that the matter composing the compound also in some way figures in its essence, if only generically (Koslicki, Form, Matter, Substance, Section III.4.2.). Either way a statement of the essence of a matter-form compound will include a reference to its form. 


\section{Kathrin Koslicki}

(6) Matter-form Relation: How is the matter composing a matterform compound related to the compound's form?

(7) Matter-compound Relation: How is the matter composing a matter-form compound related to the compound?

(8) Form: What sort of entity is the form composing a matterform compound?

(9) Matter: What sort of entity is the matter composing a matterform compound?

\subsection{Hylomorphic Monism}

Hylomorphic monists hold that matter-form compounds and their matter are numerically identical or numerically the same concrete particular object: that is, in their view, the matter-compound relation, at issue in (7), is numerical identity or numerical sameness. ${ }^{23}$ From the perspective of the monist, therefore, the region of spacetime occupied by Lumpl and Goliath, despite appearances to the contrary, is in fact occupied by only a single concrete particular object. As noted earlier, even though monists deny that Gibbard's case involving Lumpl and Goliath presents us with a genuine case of coincidence, these theorists nevertheless still face an explanatory task of their own: for monists as well must in some way account for our practice, as illustrated in (2) and (3), of attributing apparently contradictory properties to Lumpl and Goliath, despite the fact that, in their view, the region of spacetime in question is occupied by only a single concrete particular object.

Anna Marmodoro's universalist powers approach, for example, presents us with a version of hylomorphic monism. ${ }^{24}$ According to this approach, the pre-existing material ingredients (e.g. the bricks and mortar) from which a hylomorphic compound (e.g. a house) is made cease to exist as a result of the process which produces a new hylomorphic compound. Thus, there is no separate entity or collection of entities (viz. the matter or plurality of material parts composing a newly created hylomorphic compound) which is numerically

23 Some hylomorphists have tried to approach the relation between a matter-form compound and its matter by distinguishing a notion of numerical sameness that is not to be confused with the relation of numerical identity; see for example Michael Rea, 'Sameness Without Identity: An Aristotelian Solution to the Problem of Material Constitution', Ratio 11 (1998), $316-328$.

Marmodoro, 'Aristotle's Hylomorphism Without Reconditioning'. 


\section{Towards a Hylomorphic Solution to the Grounding Problem}

distinct but spatiotemporally coincident with the newly created hylomorphic compound.

Marmodoro's approach has the benefit of escaping the ontological commitments incurred by pluralists, but only at the cost of diverging dramatically from the persistence conditions we ordinarily attribute to the pre-existing entities which go into the making of a newly created hylomorphic compound. Thus, no brick can strictly speaking survive the building of a house, even when (as we would ordinarily put it) all that apparently happens to the brick, say, is that it comes to be surrounded by other bricks and connected to them with mortar. In such a case, the brick ceases to exist once it becomes 'absorbed' into the newly created house, though many of the characteristics which previously inhered in the brick prior to its destruction continue to 'live on' in the newly created house. ${ }^{25}$

\subsection{Non-Robust Hylomorphic Pluralism}

Hylomorphic pluralists deny that a matter-form compound and its matter are numerically identical or numerically the same concrete particular object: that is, in their view, numerical identity or numerical sameness are not live options for the matter-compound relation at issue in (7). The Grounding Problem challenges these theorists to explain how Lumpl and Goliath, despite the fact that they are otherwise so much alike, can nevertheless differ with respect to their sortalish profile, as illustrated in (2) and (3). Non-robust hylomorphists construe forms in the non-robust way problematized by the first horn of Sidelle's dilemma. Given this combination of views, as will become clear shortly, non-robust hylomorphic pluralists make it unnecessarily difficult for themselves to formulate a response to the Grounding Problem.

Suppose, for example, that forms are construed in the following non-robust manner: for Goliath to 'have' a certain form is simply for Goliath's material parts to be arranged in a certain way. Of course, if all it takes for an entity to 'have' a certain form is for its

25 Versions of hylomorphic monism can also be found for example in Brower, Aquinas's Ontology of the Material World: Change, Hylomorphism, and Material Objects; Jaworski, Structure and the Metaphysics of Mind: How Hylomorphism Solves the Mind-Body Problem; Oderberg, Real Essentialism; Michael Rea, 'Sameness Without Identity: An Aristotelian Solution to the Problem of Material Constitution'; and Patrick Toner, 'Emergent Substance', Philosophical Studies 141 (2008), 281-297. 


\section{Kathrin Koslicki}

material parts to be arranged in a certain way, then nothing will prevent Lumpl from also 'having' Goliath's form, f, simply by virtue of being spatiotemporally coincident with Goliath. After all, spatiotemporally coincident objects are composed of the same material parts and their material parts are arranged in the same way. Thus, given this non-robust construal of form, both Lumpl and Goliath count as standing in the very same relation to Goliath's form, merely by virtue of being spatiotemporally coincident.

But now we may ask the question posed in (4): why is it that Goliath's form, f, figures in Goliath's essence, but not in Lumpl's? In general, hylomorphic pluralists would be expected to appeal to a formal difference between Lumpl and Goliath, in order to explain their apparent sortalish differences. In this case, however, the relevant apparent sortalish difference between Lumpl and Goliath precisely concerns their relation to Goliath's form, f. Since non-robust hylomorphic pluralists hold that Lumpl and Goliath both 'have' Goliath's form, $f$, in virtue of having the same material parts arranged in the same way, it becomes utterly mysterious how an appeal to Goliath's form, f, could possibly help to explain why Goliath and Lumpl are nevertheless apparently differently related to Goliath's form, $f$, as brought out in (2) and (3).

The lesson to draw from this characterization of Gibbard's scenario is not that hylomorphic pluralists in general are unable to formulate a solution to the Grounding Problem; but rather that hylomorphic pluralists should reject the assumptions on which the non-robust construal of form and the compound-form relation are based. Where non-robust hylomorphic pluralists go wrong is that their construal suggests a reductive analysis of what it means for a compound to be related to its form in terms of conditions that are so minimal that the matter composing the compound meets these conditions as well, merely by virtue of being spatiotemporally coincident with the compound. With these impoverished resources at their disposal, it is no wonder, then, that non-robust hylomorphic pluralists have trouble explaining the apparent sortalish differences between coincident objects by appeal to their formal differences. As we will see in the next section, robust hylomorphic pluralists not only reject the minimal conditions proposed by their non-robust counterparts; they also reject the very idea that it is necessary at all for hylomorphists to give a reductive analysis of a compound's relation to its form. ${ }^{26}$

26 Sidelle quite clearly construes non-robust hylomorphic pluralism as a position which, in the course of attempting to formulate a response to the Grounding Problem, also goes in for a reductive analysis of a compound's 


\section{Towards a Hylomorphic Solution to the Grounding Problem}

\subsection{Robust Hylomorphic Pluralism: A Compositional Approach}

I endorse the following robust pluralist hylomorphic response to the Grounding Problem which incorporates views I have developed elsewhere: ${ }^{27}$ (i) numerically distinct spatiotemporally coincident objects are formally distinct, i.e. they have distinct essences; (ii) these basic essential differences between numerically distinct spatiotemporally coincident objects, when conjoined with a non-modal conception of essence, can be used to explain their derivative modal differences; and (iii) the considerations on which (i) and (ii) are based are independently motivated, i.e. based on reasons not directly related to our desire to formulate a hylomorphic response to the Grounding Problem. A response to the Grounding Problem which exhibits these three features still counts as a version of primitivism, since it takes as basic essential differences between numerically distinct spatiotemporally coincident objects. However, since the main features of this account are independently motivated and earn their keep by doing explanatory work, the robust hylomorphic pluralism I propose below does not simply deny that the apparent sortalish differences between numerically distinct spatiotemporally coincident objects need to be grounded; rather, it outlines a strategy for explaining the derivative modal differences between numerically distinct spatiotemporally coincident objects in terms of their basic essential differences.

In the remainder of Section 4.4, I focus on the first component of my response to the Grounding Problem and argue that we have independently motivated reasons for thinking that coincident objects have distinct essences. In Section 5, I turn to the second component of my strategy and discuss how an independently motivated non-

relation to its form. For example, the title of Section 2 of Sidelle's 'Does Hylomorphism Offer a Distinctive Solution to the Grounding Problem?' is 'What is it for an object to have a form?' and the question re-occurs numerous times throughout Sidelle's discussion. As Sidelle recognizes, robust hylomorphic pluralists, by contrast, reject the idea that they are obliged to give a reductive account of a compound's relation to its form, as part of their response to the Grounding Problem or for any other reason. In their view, after all, no further analysis in more basic terms can be given, or needs to be given, of a compound's relation to its form.

27 Koslicki, The Structure of Objects, especially Chapter VII; and 'Essence, Necessity and Explanation', in Contemporary Aristotelian Metaphysics (ed.) Tuomas Tahko (Cambridge: Cambridge University Press, 2012), 187-206. 


\section{Kathrin Koslicki}

modal conception of essence can be used to explain the derivative modal differences between coincident objects. Although other theorists may disagree with the details of my account, (i)-(iii) are in principle transferrable to other hylomorphic or non-hylomorphic versions of robust pluralism as well. Hence, the overall strategy I am proposing does not, and is not intended to, yield a distinctively hylomorphic solution to the Grounding Problem.

\subsubsection{Robust Mereological Hylomorphic Pluralism: The Basics}

To begin with, let's review the basic hylomorphic characterization of Gibbard's Lumpl and Goliath scenario stated above (cf. Section 4.1. (1)-(3)): Goliath is a compound of some matter, $\mathrm{m}$, and a form, f; Lumpl is Goliath's matter; Goliath's form, $f$, figures in Goliath's essence, but does not figure in Lumpl's essence. Next, given pluralism, Lumpl and Goliath, by Leibniz's Law, are numerically distinct, since they are not indiscernible with respect to all of their properties. Given robust hylomorphic pluralism, Goliath's relation to its form, $f$, is not analyzed reductively in terms of conditions that are so minimal that Lumpl, merely by virtue of being spatiotemporally coincident with Goliath, meets these conditions as well and therefore counts as standing in the very same relation to $f$ as Goliath. More generally, robust hylomorphic pluralists reject the very idea that a reductive analysis of a matter-form compound's relation to its form can be given, or needs to be given.

In addition, I supplement this basic characterization of robust hylomorphic pluralism with the following further positions. First, I adopt a hylomorphic conception of matter, according to which the material parts of matter-form compounds are themselves matter-form compounds, as long as these material parts are also structured wholes. ${ }^{28}$ Secondly, I endorse the individual forms

28 In Chapter II of Form, Matter, Substance, I consider and reject two main rival conceptions of matter: accounts which conceive of the matter composing an object as prime matter (e.g. Oderberg, Real Essentialism); and accounts which conceive of the matter composing an object as belonging to the ontological category of stuff (e.g. Ned Markosian, 'The Right Stuff', Australasian Yournal of Philosophy 93 (2015), 665-687). The approach defended by Brower in Aquinas's Ontology of the Material World: Change, Hylomorphism, and Material Objects belongs to both camps, since Brower holds that the matter constituting matter-form compounds is prime matter; but he interprets prime matter as belonging to the ontological category of stuff. 


\section{Towards a Hylomorphic Solution to the Grounding Problem}

hypothesis, according to which forms are particular or individual entities, i.e. entities that are by their very nature not repeatable or shareable among multiple distinct entities by being wholly present in each of them at a single time. Thirdly, according to the thoroughly mereological conception of composition I develop in The Structure of Objects, both the matter and the form composing a matter-form compound are literally and strictly speaking proper parts of the compound, according to a single relation of proper parthood. ${ }^{29}$

In response to the questions posed in (5)-(9), this combination of views gives rise to the following position, to which I will refer in what follows as '(RMHP)' (short for 'Robust Mereological Hylomorphic Pluralism'):

(5') Compound-Form Relation: $\mathrm{f}$ is a proper part of $\mathrm{O}$; and $\mathrm{f}$ figures in O's essence.

(6') Matter-form Relation: m satisfies constraints dictated by $\mathrm{f}$.

$\left(7^{\prime}\right) \quad$ Matter-compound Relation: $\mathrm{m}$ is a proper part of $\mathrm{O}$.

$\left(8^{\prime}\right) \quad$ Form: $\mathrm{f}$ is a robust particular which does not simultaneously bear the same relation to $\mathrm{O}$ (essentially) and to $\mathrm{m}$ (accidentally).

29 Very briefly, my argument in Chapter VII of The Structure of Objects goes as follows. In order to avoid a proliferation of primitive sui generis notions of parthood and composition, whose characteristics must be stipulatively imposed on them by means of distinct bodies of postulates (Fine, 'Things and Their Parts'), I assume a single notion of parthood, at least for the domain of concrete particular objects, which satisfies at least the following minimal formal characteristics: Asymmetry, Transitivity, and Weak Supplementation. (The Weak Supplementation Principle states that an object which has a proper part must have at least another proper part disjoint from the first.) By Leibniz's Law, a whole is not identical to its proper parts, individually or collectively, since a whole and its proper parts are not indiscernible with respect to all of their properties. Next, it is plausible to think that a matter-form compound has its matter or material components as proper parts. Suppose now that it is possible for a whole (e.g. a statue) to be composed of just a single material component (e.g. a piece of clay). Then, by Weak Supplementation, the whole must have one or more additional proper parts besides its single material component. But the best candidates for these additional proper parts within the whole are of course its form or formal components. I conclude that a whole therefore has both its matter or material components and its form or formal components as proper parts, strictly and literally speaking and according to a single relation of proper parthood. 


\section{Kathrin Koslicki}

$\left(9^{\prime}\right) \quad$ Matter: $\mathrm{m}$ is a matter-form compound (assuming that $\mathrm{m}$ is a structured whole); $\mathrm{m}$ and $\mathrm{O}$ are both concrete particular objects and hence belong to the same ontological category. ${ }^{30}$

\subsubsection{Essential Differences between Coincident Objects}

As stated in $\left(5^{\prime}\right)$ and $\left(7^{\prime}\right)$, the compound-form relation and the mattercompound relation overlap, in that both the matter and the form, in my view, are proper parts of the matter-form compound they compose. However, as brought out in $\left(5^{\prime}\right)$, the compound-form relation also includes a further dimension, in addition to the mereological relationship between a matter-form compound and its form. This further dimension concerns the close connection between form and essence: the form, according to my thoroughly mereological conception of composition, is a proper part of the matter-form compound; but, in addition to that, the form also figures in the compound's essence, either by exhausting (i.e. being identical to) its essence or by being included in its essence. (More on the connection between form and essence shortly.)

Contrary to what is assumed by non-robust hylomorphic pluralists, the matter-form relation, at issue in $\left(6^{\prime}\right)$, is not the same relation as the compound-form relation. Rather, the relation borne by the material components composing a whole to the form associated with the matter-form compound in question is that of satisfying the constraints specified by the form. As I have emphasized in previous work, among the primary responsibilities of the form within a matter-form compound is to specify a range of structural requirements which must be satisfied by the material parts composing a matter-form compound. We may think of the form associated with a matter-form compound, on the one hand, as an entity which

30 I am focused here on scenarios in which a whole is composed of a single material component. In a scenario in which a whole is composed of more than one material component, its matter in my view is a plurality of material components. In that case, each of these material components, assuming that it is a structured whole, is itself a concrete particular object that is analyzed hylomorphically as a compound of matter and form. The more precise formulation of the hylomorphic conception of matter includes the following important proviso: the material parts of matter-form compounds are themselves matter-form compounds, unless or until we reach an empirically confirmed level in the compositional hierarchy at which the material parts of matter-form compounds are not themselves structured wholes. I discuss the possibility envisaged in the proviso in more detail in Chapter II of Form, Matter, Substance. 


\section{Towards a Hylomorphic Solution to the Grounding Problem}

provides 'slots' to be filled by objects of a certain kind, i.e. a sort of 'recipe' for how to build wholes of that kind. An object's material components or matter, on the other hand, may be visualized as what fills the 'slots' specified by the object's form: the compound's material components are thus, so to speak, the 'ingredients' that are called for in the 'recipe'; they are the objects which, in a successful case of composition, in fact satisfy the conditions dictated by the object's form. These structural constraints specified by the object's form usually result in requirements concerning the type, configuration and sometimes even the number of material components from which wholes of the kind in question must be composed. In addition to these structural constraints, however, the form also sets other constraints governing the object's material components: in general, the form is that explanatory principle within a matter-form compound which accounts for the compound's structure, identity and unity. ${ }^{31}$

Given that, as stated in $\left(5^{\prime}\right)$, forms are proper parts of the matterform compounds with which they are associated, the logical properties of parthood and composition, in my view, legislate that matter-form compounds cannot be taken to be numerically identical to their individual forms: contrary to the composition-as-identity model, I hold that wholes are numerically distinct from their proper parts, individually or collectively. ${ }^{32}$ The present approach, therefore, allows us to take a stand against identity theorists who

31

I discuss the structural constraints set by the form of a matter-form compound in Koslicki, The Structure of Objects. For the form's role in determining the numerical identity of matter-form compounds, see Form, Matter, Substance, Section III.4.3; and 'Essence and Identity'. The unity of matter-form compounds is taken up in Form, Matter, Substance, Chapter VII. The three types of constraints I have just identified (i.e. constraints concerning the structure, identity and unity of a matter-form compound) are not intended to constitute an exhaustive list of all possible types of constraints which can be placed on an object's material components by the object's form. For one would expect, for example, that specific kinds of objects are governed by further formal constraints which do not generalize across the board. To illustrate, in the case of chemical kinds, for example, the material components composing a molecule, say, must be chemically bonded to one another by sharing electrons; but in the case of artifact kinds, the material components composing an ax, say, must be properly fastened to one another in a different way.

32 For diverging perspectives concerning the composition-as-identity model, see for example David Lewis, Parts of Classes (Oxford: Basil Blackwell, 1991); and Composition as Identity (eds) Aaron J. Cotnoir and Donald L. M. Baxter (Oxford: Oxford University Press, 2014). 


\section{Kathrin Koslicki}

hold that the compound-form relation at issue in (5) is numerical identity. ${ }^{33}$

Various options are open to both universal and individual forms theorists when it comes to the development of a clarified understanding concerning the relation between form and essence. Both approaches are able to represent the possibility that the essence of a hylomorphic compound is identical to its form as well as the possibility that the essence of a hylomorphic compound is not exhausted by its form, e.g. on the grounds that the matter composing it also in some way figures into its essence, if only generically. If forms are particular or individual entities, then a compound's individual essence is either exhausted by (i.e. is identical to) its individual form or it includes but is not exhausted by the compound's individual form, e.g. on the grounds that the matter also in some way figures in its individual essence, if only generically. Alternatively, if forms are universal or general entities, then the essences under discussion are generic essences shared by all members of a certain kind. Still, this latter option is also compatible with both of the possibilities just mentioned: either kind-essences are purely formal or, e.g. it is also part of the generic essence of a certain kind of hylomorphic compound that it be suitably enmattered. Either way, forms and essences are intimately linked, since the essence of a matter-form compound is either exhausted by or includes its form. ${ }^{34}$

33 The position that a concrete particular object (e.g. Socrates) should be identified with the object's individual form (e.g. Socrates' soul) is defended, for example, in Michael Frede, 'Substance in Aristotle's Metaphysics', reprinted in his Essays in Ancient Philosophy (Minneapolis: University of Minnesota Press, 1987), 72-80; Michael Frede, 'Individuals in Aristotle', reprinted in his Essays in Ancient Philosophy, 49-71; Michael Frede and Günther Patzig, Aristoteles Metaphysik Z, Text, Übersetzung und Kommentar, Vols. 1 and 2 (Munich: Verlag C. H. Beck); Lowe, 'Form Without Matter'; Jennifer Whiting, Individual Forms in Aristotle, unpublished doctoral dissertation (Ithaca: Cornell University, 1984); Jennifer Whiting, 'Form and Individuation in Aristotle', History of Philosophy Quarterly 3 (1986), 359-377; Jennifer Whiting, 'Metasubstance: Critical Notice of Frede-Patzig and Furth', The Philosophical Review 100 (1991), 607-639; and Jennifer Whiting, 'Living Bodies', in Essays on Aristotle's De Anima (ed.) Martha C. Nussbaum and Amélie Oksenberg Rorty (Oxford: Clarendon Press, 1992), 75-91.

34 Beyond that, additional commitments concerning the precise specification of the essence of a matter-form compound require delving more deeply into what it means to be an object of a specific kind. To illustrate, for the specific case of artifacts, say, to state exactly what goes into the 


\section{Towards a Hylomorphic Solution to the Grounding Problem}

According to (RMHP), Goliath's form, f, is a proper part of Goliath. Even though Lumpl is coincident with an object, viz. Goliath, which has $f$ as a proper part, $f$ is not therefore also a proper part of Lumpl. Recall that robust hylomorphic pluralists reject the idea that they are under any obligation to give a reductive analysis of a compound's relation to its form. Thus, the fact that Lumpl occupies the very same region of spacetime as an object, viz. Goliath, that has Goliath's form, f, as a proper part, is not a reason for thinking that Lumpl must therefore also have $f$ as a proper part. Although I have adduced general philosophical reasons in my previous work for thinking that a matter-form compound has its form as a proper part, these arguments are not offered in the spirit of giving a reductive analysis of the relation between a matter-form compound and its form. Rather, as a proponent of (RMHP), I maintain that it is a basic fact about Lumpl and Goliath that they differ with respect to their formal parts.

Turning now to $\left(8^{\prime}\right)$, we can use the basic outlines of (RMHP) to bring us one step closer toward the larger goal of arriving at a clarified understanding of what sorts of entities forms are. Given the robust construal of forms, we know that forms cannot be reductively analyzed in terms of a set of minimal conditions which are simultaneously met by the compound's matter, merely in virtue of the fact that it materially composes the compound. These further constraints

specification of an artifact's essence requires a commitment to a particular essentialist account of artifacts. But those who have proposed such accounts disagree with one another as to what exactly belongs into a proper specification of the essence of an artifact (e.g. its function, the particular creative intention guiding the artifact's maker, the artifact's original matter, the particular creative act in which the artifact's maker successfully exercised his or her creative intention, etc.). In addition, in the case of artifacts, we must of course confront the more general question as to whether a coherent and plausible essentialist account is even possible or appropriate, given that artifacts seem to be in certain ways dependent on human minds, interests, practices, and so forth. For further discussion of the particular case of artifacts, see for example Lynne Rudder Baker, The Metaphysics of Everyday Life: An Essay in Practical Realism (New York: Cambridge University Press, 2007); Evnine, Making Objects and Events: A Hylomorphic Theory of Artifacts, Actions, and Organisms; Koslicki, Form, Matter, Substance, Chapter VIII; and Amie Thomasson, 'Realism and Human Kinds', Philosophy and Phenomenological Research 67 (2003), 580-609. 


\section{Kathrin Koslicki}

that are placed on our conception of forms by the robust construal are not specific enough to single out a particular choice among the range of ontological categories available to individual forms theorists. But they do narrow down our options to some extent by removing from our consideration approaches according to which forms are construed non-robustly. ${ }^{35}$ If we want to cut down the range of viable options available to individual forms theorists even further beyond their status as robust particulars, this choice must be made on independent grounds which go beyond the considerations raised here.

Next, as stated in $\left(9^{\prime}\right)$, Lumpl, i.e. Goliath's matter, given the hylomorphic conception of matter, is itself to be construed as a matterform compound, $\mathrm{O}^{*}$, consisting of some matter, $\mathrm{m}^{*}$, and a form, $\mathrm{f}^{*}$, assuming that Lumpl is also a structured whole:

$$
\mathrm{O}^{*}=\mathrm{m}^{*}+\mathrm{f}^{*}
$$

Therefore, Lumpl, on this view, belongs to the very same ontological category as Goliath; i.e. both are concrete particular objects and both are analyzed as matter-form compounds, assuming that Lumpl and Goliath are structured wholes. The same reasons which motivate us to hold that Goliath has its matter, i.e. Lumpl, and its form, $\mathrm{f}$, as a

35 As noted earlier, individual forms theorists have a range of options available to them, depending on whether they take individual forms to be objects, properties, relations, powers, states, functions, activities, processes, facts, actions, sui generis entities, or what have you. (In each case, the ontological category in question is of course construed as containing particulars as its members.) The robust construal of individual forms does not in itself favor one of these ontological categories over another; rather, it rules out certain conceptions of what the occupants of the relevant ontological category are like. The robust construal of forms requires that - regardless of what sorts of entities individual forms are - they cannot bear the very same relation both to the compound (essentially) and to the matter (accidentally). Thus, suppose for example that Socrates' individual form is construed as a particularized property (e.g. a humanity trope) which essentially characterizes Socrates. Then, the robust construal requires that Socrates' humanity trope does not also characterize Socrates' matter, viz. his body, even accidentally, despite the fact that Socrates and Socrates' body are of course spatiotemporally coincident for as long as Socrates is alive. Nevertheless, so the robust hylomorphic pluralist reasons, nothing that is human at all is human only accidentally. Therefore, even though Socrates' body is spatiotemporally coincident with an object, viz. Socrates, which is characterized by Socrates' humanity trope and is so essentially, Socrates' body is not therefore also characterized by Socrates' humanity trope, even accidentally. 


\section{Towards a Hylomorphic Solution to the Grounding Problem}

proper part, apply to Lumpl as well; therefore, we construe Lumpl similarly as a hylomorphic compound which has both its matter, $\mathrm{m}^{*}$, and its form, $\mathrm{f}^{*}$, as proper parts.

Notice that it now follows, perhaps surprisingly, that Lumpl's form, $\mathrm{f}^{*}$, is also a proper part of Goliath: for $\mathrm{f}^{*}$ is a proper part of Lumpl; Lumpl is a proper part of Goliath; the proper parthood relation which relates Lumpl's form, f*, to Lumpl is the very same proper parthood relation as that which relates Goliath's matter, viz. Lumpl, to Goliath; and, finally, this single relation of proper parthood is transitive. Since Lumpl's form, f*, is a proper part of a proper part of Goliath (viz. Lumpl), f* is therefore also a proper part of Goliath. Nevertheless, we should not infer from the fact that Lumpl's form, f*, is a proper part of Goliath that Lumpl's form, $\mathrm{f}^{*}$, is therefore also Goliath's form or that it must therefore also figure in Goliath's essence. Rather, I take it to be a basic fact about Goliath that $\mathrm{f}$, and not $\mathrm{f}^{*}$, is Goliath's form and that $\mathrm{f}$, and not f*, figures in Goliath's essence; and correspondingly for Lumpl and its relations to $\mathrm{f}$ and $\mathrm{f}^{*}$, respectively. Just as robust hylomorphic pluralists reject the idea that a reductive analysis of a matter-form compound's relation to its form can be given or needs to be given, so proponents of a non-modal conception of essence reject the idea that a reductive analysis can be given or needs to be given of facts about the essences of objects.

We can now return to the question, posed earlier in (4), concerning the particular sortalish difference between Lumpl's and Goliath's respective relationship to Goliath's form, f: 'In virtue of what it is the case that $\mathrm{f}$ figures in O's essence, but not in m's essence?'. Insofar as (4) issues a request for a reductive analysis of why Goliath and Lumpl have distinct essences, this question must be rejected as misguided. The best we can do is to respond to (4) by pointing out that it is a basic fact about Goliath that $\mathrm{f}$ (but not $\mathrm{f}^{*}$ ) figures in its essence, and a basic fact about Lumpl that $f^{*}$ (but not $f$ ) figures in its essence. In addition, general philosophical reasons can be adduced for preferring a thoroughly mereological conception of composition and a non-modal conception of essence over rival approaches. Beyond that, however, we must simply accept that all explanation comes to an end once we have reached facts about the essences of matter-form compounds that are taken as basic by the approach in question. While the basic essential differences between Lumpl and Goliath therefore cannot be further explained in terms of anything more basic, the fact that coincident objects have distinct essences, as we will see in the next section, can be used, in conjunction with 


\section{Kathrin Koslicki}

a non-modal conception of essence, to explain why they differ with respect to their derivative modal profile. ${ }^{36}$

\section{Explanatory Work for Non-Modal Essences}

As noted earlier, pluralists, in my view, can hope to make some headway towards formulating a response to the Grounding Problem, if they combine their analysis of concrete particular objects with a non-modal conception of essence. ${ }^{37}$ According to such approaches,

36 I said earlier that I will not lean on any special features concerning the specific example under discussion which arise from the fact that Lumpl and Goliath are artifacts, since I want to leave open the possibility that a similar case can in principle be constructed for living or non-living members of non-artifactual kinds as well. Given that Lumpl and Goliath are assumed to be artifacts, however, various options are available in this particular case which may not generalize to a case involving the members of natural kinds. For example, suppose that the expression, 'statue', singles out a genuine kind, but the expression, 'piece of clay', does not single out a genuine kind. Then, the plurality of material parts composing Goliath compose a matter-form compound which belongs to the kind, statue, but they fail to compose an additional matter-form, viz. the alleged piece of clay, Lumpl, which is spatiotemporally coincident but numerically distinct from the statue, Goliath. The strategy just outlined allows for a monist response to the particular case at hand. I consider the special features of artifacts in greater detail in Koslicki, Form, Matter, Substance, Chapter VIII.

37 See especially Kit Fine, 'Essence and Modality', Philosophical Perspectives 8 (1994), Logic and Language, 1-16; 'Senses of Essence', Modality, Morality, and Belief, Essays in Honor of Ruth Barcan Marcus (eds) Walter Sinnott-Armstrong, Diana Raffman, and Nicholas Asher (New York: Cambridge University Press, 1995), 53-73; 'The Logic of Essence', Fournal of Philosophical Logic 24 (1995), 241-273. Other contemporary neo-Aristotelians, myself included, have also gravitated towards a non-modal conception of essence, e.g. Michael Gorman, E.J. Lowe, and David Oderberg. The conception of essence and necessity advanced by Bob Hale is similar in many ways to Fine's, though the label 'non-modal' strictly speaking does not apply to it, since Hale takes as basic certain modal truths, viz. the essential truths, from which other necessary truths are supposed to be derivable; see his Necessary Beings: An Essay on Ontology, Modality, and the Relations Between Them (New York: Oxford University Press, 2015). For my purposes, however, we can subsume Hale's account under the label, 'non-modal', as it is used in the text, since I have in mind primarily approaches which reject the reduction of essence to modality and which hold instead that, if any such reduction is possible at all, it would have to proceed in the opposite direction. The contrasting 


\section{Towards a Hylomorphic Solution to the Grounding Problem}

certain facts about the essences of concrete particular objects are taken as basic and other facts concerning their modal profile (viz. facts about what is necessary but non-essential to these objects) are regarded as, at least in part, derivable from these primitive facts about their essences. As a result, a hylomorphic analysis of concrete particular objects, when combined with a suitable conception of essence, can hope to explain certain of the differences which obtain between numerically distinct spatiotemporally coincident objects, viz. differences with respect to their modal profile, in terms of differences between their respective essences, together with whatever further considerations turn out to be relevant to the derivation of the non-essential but necessary features of hylomorphic compounds from facts about their essences.

As I have argued in previous work, ${ }^{38}$ to make headway in explaining how the necessary accidents inhering in a hylomorphic compound follow from its essence, it is likely that we find ourselves having to appeal not just to the essence of the hylomorphic compound in question, but also to facts about the essences of distinct but related entities. To illustrate, as Aristotle brings out in his biological treatises, there is no reason to expect that the necessary (but non-essential) features of camels, say, can be derived solely from facts about the essences of camels. Rather, when we inspect Aristotle's reasoning in these texts, it becomes evident that he takes facts about the essences of various other types of entities (e.g. animals and living organisms in general, stomachs, desertous regions or earthy material) also to be relevant to a proper explanation of why camels have the particular necessary (but non-essential) features they do. To illustrate, the fact that the palates of camels are hard and durable, so Aristotle reasons, is at least in part to be explained by reference to the fact that the palates of camels are made of earthy material. But the fact that things made of predominantly earthy material are hard and durable, for Aristotle, is itself directly traceable to facts about the essence of earth, one of the four elements

model, which does take essence to be reducible to modality, dominated the metaphysical landscape for many decades starting in the 1970s. For some representative examples, see for example Graeme Forbes, The Metaphysics of Modality (Oxford: Oxford University Press, 1985); David Lewis, On the Plurality of Worlds (Oxford: Basil Blackwell, 1986); Penelope Mackie, How Things Might Have Been: Individuals, Kinds, and Essential Properties (New York: Oxford University Press, 2009); and Alvin Plantinga, The Nature of Necessity (Oxford: Clarendon Press, 1974).

38 Koslicki, 'Essence, Necessity and Explanation'. 


\section{Kathrin Koslicki}

which, in Aristotle's view, materially compose the inhabitants of the sublunary sphere in different ratios. Thus, an account of why camels have the particular necessary (but non-essential) features they do (e.g. hard and durable palates) may also terminate in facts about the essences of other types of entities which are in some way implicated, in particular, in the activities, physiology or habitat of camels.

Such an approach is compatible with both the individual forms hypothesis and the universal forms hypothesis, as long as the modal properties which are supposed to be explained by reference to basic facts about essences are general modal properties, i.e. modal properties which are shared by all (or at least typical) members of a kind. If, however, some of the modal properties at issue are peculiar to particular matter-forms compound, then kind-essences of course will not do the trick. I have argued that some such modal properties, viz. those concerning the crossworld identity and distinctness of concrete particular objects, are in fact peculiar to particular matter-form compounds and should be explained by appeal to facts about the numerical identity and distinctness of their individual forms. ${ }^{39}$ Thus, proponents of the individual forms hypothesis can help themselves to the following consideration in favor of their view: assuming that particular matter-form compounds have peculiar modal properties (i.e. modal properties that are unique to these matter-form compounds and not shared by other members of the same kind), individual forms offer a better prospect for allowing us to ground these peculiar modal properties in the essences of matter-form compounds than do universal forms.

A response to the Grounding Problem which utilizes a non-modal conception of essence will of course not serve to explain all the differences which obtain between numerically distinct spatiotemporally coincident objects in terms of other more basic features; rather, it assumes that all such explanations must eventually bottom out once we have reached certain basic non-modal facts about essences. To illustrate, suppose for example that a specification of Socrates' essence makes reference to the fact that Socrates is a living organism that is composed of a human soul and a suitable body, while no reference to a human soul is included in a specification of the essence of Socrates' body. Then, the question of why a specification of Socrates' essence includes a reference to a human soul, while a specification of the essence of Socrates' body does not include a reference to a human soul, cannot be expected to receive an answer in more

39 Koslicki, Form, Matter, Substance, Section III.4.3; and 'Essence and Identity'. 


\section{Towards a Hylomorphic Solution to the Grounding Problem}

basic terms, since non-modal facts about the essences of matter-form compounds are assumed to be explanatorily basic according to the approach at issue. Given this difference between Socrates' essence and the essence of Socrates' body, however, certain of the other derivative modal differences between a hylomorphic compound and its matter can now be explained by appeal to their basic essential differences, e.g. why upon Socrates' death his body slowly starts to deteriorate, whereas during Socrates' lifetime his material parts interact and hang together in a sufficiently unified manner to allow Socrates to engage in various activities that are characteristic of human and non-human animals, e.g. perceiving, sleeping, dreaming, procreating, moving, etc.

The crucial piece of apparatus which is still missing from the robust pluralist response to the Grounding Problem just outlined is a proper treatment of the relation of 'following from' which, according to a non-modal conception of essence, connects basic non-modal facts about the essences of hylomorphic compounds to their derived modal profile. As I discuss in previous work, both Aristotle and Kit Fine, in their conception of the relation between essence and modality, rely on such a distinction between what belongs to the essence proper of an object and what merely follows from the essence proper of an object. ${ }^{40}$ On both Fine's and Aristotle's conception, the de re necessary truths state the necessary (but non-essential) features which merely follow from, but are not included in, the essence proper of an object. In order for this type of approach to the relation between essence and necessity to be successful, we must be able to identify an appropriate consequence relation which generates the result that the de re necessary truths about objects follow from basic truths about their essences. For example, supposing that a specification of the essence of triangles makes reference to the fact that triangles have three angles, but not to the necessary but non-essential fact about triangles that they have three sides, then we must be given some indication of how the second fact derives from the first.

The approach Fine defends in his pioneering work on essence and modality in the 1990s certainly has an advantage over the traditional modal conception of essence, in that it is set up to reflect the sensitivity of essential truths towards their grounds, viz. facts concerning the identity of those objects in virtue of which these claims are true. But

40 Koslicki, 'Varieties of Ontological Dependence', in Metaphysical Grounding: Understanding the Structure of Reality (eds) Fabrice Correia and Benjamin Schnieder (Cambridge: Cambridge University Press, 2012), 186-213; and 'Essence, Necessity and Explanation'. 


\section{Kathrin Koslicki}

in this work Fine assumes that the relevant consequence relation which connects propositions stating what is necessary but nonessential to objects to propositions stating what is essential to them is that of logical entailment. ${ }^{41}$ A triangle's being three-sided, however, is not logically entailed by its being three-angled, unless additional premises are added which take the relationship in question for granted and hence make the derivation in question philosophically uninteresting (e.g. that every closed geometrical figure with three angles also has three sides and that triangles are closed geometrical figures).

Aristotle's central idea, in contrast, is that the explanatory power of definitions (statements of the essence) derives from the causal power of essences. ${ }^{42}$ This approach has the potential to open the door to a philosophically satisfying account of the distinction between what belongs to an entity's essence proper and what merely follows from its essence. The relevant consequence relation which characterizes this contrast, according to Aristotle, is that supplied by his technical concept of demonstration [apodeixis], as developed in the Posterior Analytics. Demonstration encompasses more than deductive entailment, in that the explanatory order of priority represented in a successful demonstration must mirror precisely the causal order of priority present in the phenomena in question. In particular, as essences are the causal bedrock of Aristotle's metaphysics, so definitions, the linguistic counterparts of essences, are the explanatory bedrock of Aristotle's theory of demonstration. Armed with a suitable analysis of causation, Aristotle's central idea, viz. to trace the explanatory power of definitions to the causal power of essences, thus points

41 See also Hale's distinction between 'direct' and 'indirect' essential truths (Necessary Beings: An Essay on Ontology, Modality, and the Relations Between Them, 154). The direct essential truths are those propositions which are immediately, or directly, true in virtue of the nature of the entities under consideration, i.e. whose truth is guaranteed by the entity's definition. The indirect essential truths, in Hale's view, are those which logically follow from an entity's definition.

42 Aristotle divides up the causal responsibilities within a matter-form compound between the matter, which serves as the material cause of the hylomorphic compound, and the form, which serves as the formal, final and efficient cause of the hylomorphic compound. For further discussion of the causal priority Aristotle assigns to the form of a matter-form compound over the matter-form compound itself and its matter, see my 'The Causal Priority of Form in Aristotle', in Studia Philosophica Estonica 7/2 (2014), Special Issue: 'Aristotelian Metaphysics: Essence and Ground' (eds) Riin Sirkel and Tuomas Tahko, 113-141. 


\section{Towards a Hylomorphic Solution to the Grounding Problem}

the way towards a promising direction to pursue for those who are in search of an appropriate non-logical asymmetric explanatory connection between basic non-modal facts about the essences of objects and derivative facts about their modal profile. ${ }^{43}$

\section{Conclusion}

In this paper, I examined the question of how hylomorphists should respond to the challenge issued by the Grounding Problem. The Grounding Problem asks why an object and its matter (e.g. a statue and the clay that constitutes it) can apparently differ with respect to certain of their properties (e.g. the clay's ability to survive being squashed, as compared to the statue's inability to do so), even though they are otherwise so much alike. I argued for the following robust pluralist response to the Grounding Problem.

According to a robust construal of forms, a matter-form compound's relation to its form cannot be reductively analyzed in terms of conditions that are so minimal that they are met simultaneously by the compound itself (essentially) and by its matter (accidentally) merely by virtue of the fact that they are spatiotemporally coincident. In fact, robust hylomorphic pluralists reject the very idea that a reductive analysis of a compound's relation to its form can be given or needs to be given. In combination with my independently motivated endorsement of the individual forms hypothesis, we thus arrive at a construal of forms as robust particulars. A form's status as a robust particular does not single out a specific choice from among the range of ontological categories that are available to individual forms theorists; but the arguments I have presented here do serve to narrow down our options further to some extent, by removing from our consideration approaches which take forms to be nonrobust particulars.

In addition, my response to the Grounding Problem follows the thoroughly mereological conception of composition I developed in The Structure of Objects, which holds that a matter-form compound has both its matter and its form literally and strictly speaking as proper parts, according to a single relation of proper parthood.

43 This causal approach to essences is, for example, developed further in Michail Peramatzis, 'Aristotle's Hylomorphism: The Causal-Explanatory Model', forthcoming in Metaphysics: Fournal of the Canadian Metaphysics Collaborative, Vol. 1 (2018): "Hylomorphism", edited by Margaret Cameron, Kathrin Koslicki, and Michael Raven (Ubiquity Press). 


\section{Kathrin Koslicki}

Given the close connection between form and essence, a compound's relation to its form includes a further dimension, which goes beyond their mereological connection: for the compound's form also figures in the compound's essence either by exhausting (i.e. being identical to) the compound's essence or by being included in the compound's essence, along with whatever else turns out to be essential to the compound in question. Given robust mereological hylomorphic pluralism, it is a basic fact about the essences of coincident objects that they differ with respect to their formal parts. When combined with a non-modal conception of essence, this approach leads to a promising strategy for how the derivative modal differences between coincident objects may be grounded in their basic essential differences.

One outstanding piece of the puzzle, which is still needed in order to complete the response I outlined in the foregoing remarks, is a proper treatment of the relevant asymmetric consequence relation which connects what is strictly speaking part of the essence proper of an entity and what is merely necessary (but not essential) to it. While this 'following from' relation must be distinguished from logical entailment, a positive treatment of it (e.g. in terms of a suitable notion of causation) poses an, as of yet, still open research project for robust hylomorphic and non-hylomorphic pluralists who are sympathetic to a non-modal conception of essence.

University of Alberta kathrin.koslicki@ualberta.ca 